\title{
A New Paradigm for Designing Corrosion Resistant Materials
}

JAMES E. SAAL ${ }^{1}$, CLARA NYBY ${ }^{2}$, JOHN SCULLY ${ }^{3}$, WOLFGANG WINDL ${ }^{4}$, CHRISTOPHER TAYLOR ${ }^{5}$, JOHN VIENNA $^{6}$, JIE LIAN $^{7}$, GERALD S. FRANKEL ${ }^{8 *}$

${ }^{1}$ Citrine Informatics, Redwood City, CA (jsaal@citrine.io)

${ }^{2}$ Citrine Informatics, Redwood City, CA (cnyby@citrine.io)

${ }^{3}$ The University of Virginia, Charlottesville, VA (jrs8d@virginia.edu)

${ }^{4}$ The Ohio State Univeristy, Columbus, $\mathrm{OH}$ (windl.1@,osu.edu)

${ }^{5}$ The Ohio State Univeristy, Columbus, $\mathrm{OH}$ (taylor.2770@osu.edu)

${ }^{6}$ Pacific Northwest National Laboratory, Richland, WA (john.vienna@pnnl.gov)

${ }^{7}$ Rensselaer Polytechnic Institute, Troy, NY (lianj@,rpi.edu)

${ }^{8}$ The Ohio State Univeristy, Columbus, $\mathrm{OH}$ (frankel.10@,osu.edu)

Corrosion, the environmental degradation of materials, is a complex process that depends on details of the material and the environment. Metals, glasses and ceramics all undergo corrosion processes, and predicting the degradation of all three of these material classes is important for the design of a mined geologic nuclear waste repository that should prevent the release of dangerous radionuclides for a performance period of $>10^{5} \mathrm{y}$. Decades of study of corrosion processes have led to considerable fundamental understanding of various effects of the environment and material structure and composition. However, the design process of new materials for corrosion resistance has been largely trial and error. This talk will present an Integrated Computational Materials Engineering (ICME) approach to the design of corrosion-resistant metal alloys, glasses and ceramics as part of a DoE Energy Frontier Research Center (EFRC). Results from studies on glass and ceramic materials will be reviewed, and then efforts to design corrosion resistant high entropy alloys will be presented. Finally, recent work on the use of machine learning and materials informatics to develop predictive models for corrosion performance will be presented. 